\section{The Newer Neurology}

To the Editor:-In The Jocrxal, March 20, 1909, p. 982, Dr. Blackburn still classifies acute anterior poliomyelitis as a "system disease"-a disease of the lower motor segmentin his scheme for a "postgraduate course for county societies." This is unfortunate, for it represents an old and discarded conception and helps to keep alive the confusion and pessimism among general practitioner's in regard to neurology.

The idea that acute anterior poliomyelitis is a disease of the lower segment had its origin with Charcot, who based his pathology and classification on cases examined only in the late and chronic stages.

It is recognized to-day that acute anterior poliomyelitis is merely a form of myelitis; primarily a vascular or inflam. matory tronl,e, which, for anatomical reasons, is more or less confined to the anterior horns of the cord. The chromatolytic changes in the ganglion cells are consecutive or associated phenomena. The latter, however, do not classify the disease as a primary "systemic" trouble of the lower motor segment any more than the degeneration observed in the pyramidal cortical neurones; after a cerebral apoplexy or inflammation, make of the former a primary systemic disease of the upper motor segment. Without referring to my work and the emphasis laid therein on this modern conception of the disease, I will quote the words of Starr in the last edition (1907) of his "Nervous Diseases": "The majority of recent pathologists believe that in anterior poliomyelitis there is an acute inflam. matory process limited to the domain of the anterior spinal arteries, involving both the neuroglia and the ganglion cells and resulting in degeneration and atrophy both of the interstitial tissue and of the ganglion cells. . . . In a number of cases, the explanation of the origin of the process is found in a thrombosis of one of the branches of the spinal artery or in a hemorrhage into the anterior horn."

In a word, then, acute anterior poliomyelitis is a myelitis, a vascular trouble primarily. The chromatolytic changes in the ganglion cells whereon the old Charcot conception of the discase was based, and whereby it is to-day classified by belated students of neurology as a "system" disease of the lower motor segment, are of the nature of mere consecutive or as. sociated phenomena.

The distinction between the two conceptions has a most important bearing on the etiology, prognosis and treatment of the disease, as $I$ have shown elsewhere.

\section{Harrison Mettler, Chicago.}

\section{Accident Insurance}

To the Editor:-The case reported by Dr. Robert T. Morris in TuE Jocrnal, Narch 13, under the title, "Appendicitis and Accident Insurance," induces me to report a case now going through the courts in Iowa.

A traveling passenger agent, aged 62 , in perfect health and an unusual specimen of physical manhood, who had never previously had a severe illness, found one morning that his regular defecation was impossible in consequence of agonizing pain in the rectum on the slightest attempt. After soveral ineffective efforts, at his wife's suggestion and in her presence he lubricated his finger with vaselin. and with difficulty re. moved from the rectum a piece of fish bone which hall been canght there transversely. He recognized from the blood at the time that he hat injured himself. This bappened in Chicago on Monday morning. On Tueslay afternoon I saw him at my office, received the above history, and examined him vithout any instrumentation. Just within the sphincter was a trar of the mucous membrane about three-quarters of an inch long. This was cleansed and touched with solution of tincture of iodin, carbolic acid and chloral hydrate. From this slight lesion a most severe case of septic infection developed. The whole cellular tissue of penis, scrotum and ischiorectal fossin, and of the intermuscular abdominal planes, was suecessively invaded, became gangrenous, and death ensued.

The patient held accident insurance in several companies. On the third day I assisted him to make out the necessary reports required by the poliries. All the companies but me immediately paid the insurance. The one company declined payment on the ground that the terms of the contract had not been complied with, inasmuch as the deceased had not norified the company of the date and nature of the accident, which it contended, within the meaning of the law and the contract, occurred when the insured swallowed the bone! The widow brought suit, plaintiff's attorney arguing that not the swallowing of the bone, but the laceration of the mucous membrane and consequent infection, constituted the accident. The presiding judge sustained the plaintiff. The case was ap. pcaled by the accident company, and is now before the higher court.

The absurdity of the company's contention, which would require a policy holder to "keep tab" on all the foreign and toxic substances present in his daily food, and, whether con. scious at the time of the fact or not, to report to the com. pany that he had "swallowed something" by accident that might eventually prove injurious, is obvious.

\section{J. H. Greexe, M.D., Dubuque, Ia.}

\section{Benzoáte of Soda in Foods}

March 20, 1909.

To the Editor:-I mrst request you to correct a misrepresentation of the position relative to sodium benzoate in my letter published March 13. If your correspondent of the current issue had read the letter with sufficient care, he would lave learned that $w$.at I "put perfectly clear" was that the argument against sodium benzoate produces the impression of an effort to mislead the public rather than to give due regard to the facts. Considering that we liave not yet seen the report of the referee board, and, moreover, since it has not yet been made public, that the board is not in a position where it can defend its conclusions, we must realize that, especially in view of the eminence of those composing the board, any criticism of their conclusions at this time is premature and ill advised. If we recall that ripe rot is the normal method by which vegetable matter tends to return to the earth from which it has grown in plant construction, we should know that deeay is not due to the careless handling of raw material, but is the inevitable result of exposure to the air of all succulent vegetable products that do not con. tain preservative.

We need only consult our materia medica to note that acetic acid, all of the many spices, salt, sugar, onions, garlic, in fact, all of the ingredients catchup excepting tomato itself are drugs, as well as sodium benzoate; yet these are all allowed in food without regard to the possibility that they may not be harmless when indiscriminately used by "infants, children and those wavering between life and death." We must avoid confusing an essentially injurious quality with the possibility of an injurious effect from unusual conditions, such as the ingestion of inordinate quantities. Anything and everything, including the most nutritious food, may be deleterious under exceptional circumstances. What we have to determine with a given substance is whether ic is essentially injurious or whether it resembles other food ingredients in becoming so only under some unusual conditions.

\section{E. E. Smith, M.D., New York City.}

\section{Compound Comminuted Fracture of the Hip Followed by Bony Union and Movable Joint}

To the Editor:-In ThE Jockxal, Aug. 4. 1906. I reported a case of gunshot wound through the great trochanter and hip joint, from which shot pieces of clotbing, gun wads and fragments of bone were removed. The patient, a farmer, recently presented himself for examination and the findings are such that I am sure that they will be of interest to the profession generally. The man is able to do his work as well as ever. There is three-quarters of an inch shortening, for which he wears a slight elevation of the heel of his shoe. Fvery motion in the joint is almost perfect. I believe that the excellent results in this case are due to the facts that the wound was filled with Moorhof's bone wax, and that the twoway extension of Maxwell was applied.

James E. Moore, Minneapolis. 